\title{
Maxillofacial Injury due to Pressure Cooker Explosion in a 13-year-old child: Surpassing The Obvious
}

\author{
Kabiraj Poudel, ${ }^{1}$ Bandana Koirala, ${ }^{2}$ MamtaDali, ${ }^{3}$ Sneha Shrestha ${ }^{4}$ \\ ${ }^{I}$ Post-graduate Resident, ${ }^{2}$ Professor, ${ }^{3}$ Associate Professor, ${ }^{4}$ Assistant Professor \\ ${ }^{1-4}$ Department of Pedodontics and Preventive Dentistry, College of Dental Surgery, \\ B.P. Koirala Institute of Health Sciences, Dharan, Nepal.
}

\begin{abstract}
Pediatric maxillofacial trauma is quiet commonly encountered in the pediatric emergency department. Management of pediatric maxillofacial trauma depends upon the cause and extent of the injury. Maxillofacial trauma due to the explosion of pressure cooker is rare in children. Here, we report a case of pediatric maxillofacial injury due to the explosion of pressure cooker in a domestic setting.

Keywords: Explosion, maxillofacial trauma, pediatric, pressure cooker.
\end{abstract}

\section{INTRODUCTION}

Pediatric maxillofacial injury is a very commonly encountered phenomenon. The common causes of trauma include motor vehicle accidents followed by other accidental causes such as sports related injuries, violence, falls etc. ${ }^{1}$ However, maxillofacial injury due to pressure cooker blast in pediatric population is rare. ${ }^{2}$ Pressure cooker blast incidents are mostly due to improper use of the device or faulty apparatus itself. Though the misuse of pressure cooker as an explosive is also not uncommon. ${ }^{3}$ Pressure cookers used for domestic purposes are associated with different forms of injuries ranging from minor cuts, burns and scalds to major mishaps involving fire accidents and bursts. ${ }^{4}$

\section{CASE REPORT}

A 13-year-old female child reported to the pediatric emergency department due to injury by pressure cooker

\section{Correspondence}

Dr. Kabiraj Poudel

Post-graduate Resident

Department of Pedodontics and Preventive Dentistry,

College of Dental Surgery,

B.P. Koirala Institute of Health Sciences, Dharan, Nepal.

E-mail: drpoudelkabiraj@gmail.com

\section{Citation}

Poudel K, Koirala B, Dali M, Shrestha S. Maxillofacial Injury due to Pressure Cooker Explosion in a 13-year-old child: Surpassing The Obvious. J Nepal Assoc Pediatr Dent. 2020;1(1):20-2. blast while cooking. As per the informant she was taken to a nearby zonal hospital where the primary management of wound irrigation and en-masse suturing was done to control the bleeding. She was then referred to the higher center for further management. On presentation in the emergency department, there was an extra-oral lacerated wound over the right cheek region measuring approximately $6 \mathrm{~cm}$ in maximum dimension and extending from the lower eyelid till the temporomandibular joint area. En-mass suture was present in the wound with no active bleeding from the wound (Figure 1). The buccal mucosa underneath was intact. In addition, the patient had a lacerated wound over the right upper eyelid causing difficulty in opening her right eye. Her vitals were within the normal limits, but she was very apprehensive and stressed.

The child and both the parents were counseled regarding the treatment procedures along with the needed psychological support. After completing preliminary routine investigations, the previous sutures were removed, and the wound was explored thoroughly under local anesthesia to check for any embedded foreign body or metallic parts. The wound was deep, involving the muscle layers and extending till the maxillary and zygomatic bone but the underlying bony architecture, parotid gland and ducts were intact. Thereafter, primary closure of the wound was done by using multilayered suturing technique (Figure 2). 


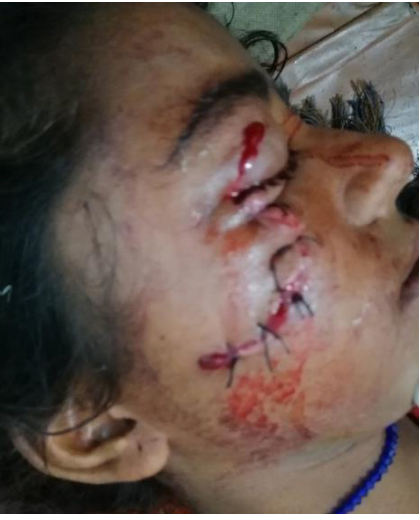

Figure 1. Preoperative: With en-mass sutures placed at a zonal hospital.

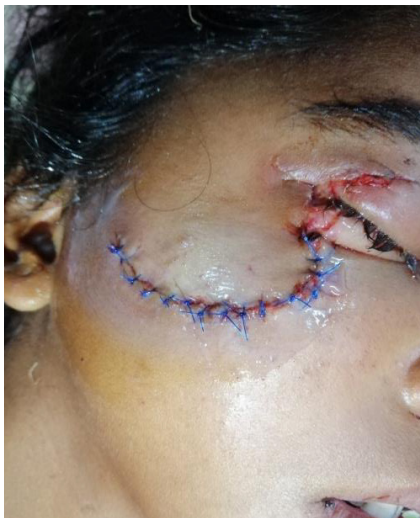

Figure 2. Post operative: After wound debridement and multilayered suturing.
Ophthalmology consultation was also made regarding the difficulty in eye opening. The patient was kept on analgesics and antibiotics and under regular follow until the satisfactory wound healing was seen (Figure 3). The patient turned up for a follow up after 3 months and the wound had healed properly but with a scar (Figure 4).

\section{DISCUSSION}

The injury caused due to pressure cooker can range from burns to mechanical trauma. The heat from the outer surface of the pressure cooker can cause burn injuries. Scalds can be caused to the person nearby by the steam under pressure escaping from the nozzle. Sometimes, the hot nozzle and lid may escape and can cause serious damage which can be a combination of mechanical injuries and burns. ${ }^{2}$ Injuries due to the improvised explosive devices (IED) were also common during the 13 years conflict period in Nepal and still prevail..$^{5-7}$ The most common form of IED included Socket, Sutali, and Pressure cooker bombs. ${ }^{5}$ Literature regarding accidental domestic pressure cooker injuries mostly include ocular injuries, penetrating facial injuries and traumatic brain injuries. $^{8}$

Though pressure cooker related traumatic brain injury in pediatric population is reported in the literature, only one pressure cooker related maxillofacial injury in children could be found. ${ }^{9}$ Most of these cases of pressure cooker related injuries had penetrating foreign bodies. The search for foreign body is a must as pressure cooker blast might have metal impinged over the injured site. ${ }^{2,4}$ In this case as per the parents who witnessed the accident, cause of pressure cooker injury was by whole of the lid, which

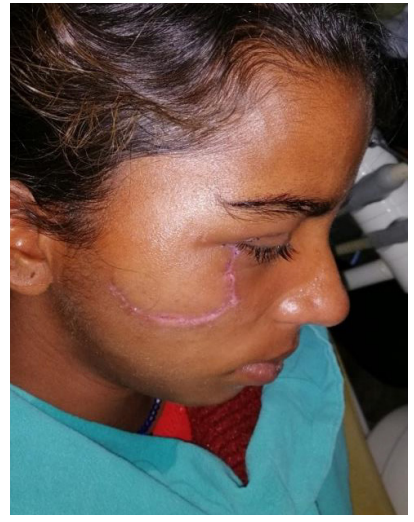

Figure 3. Wound healing at 7 days follow up.

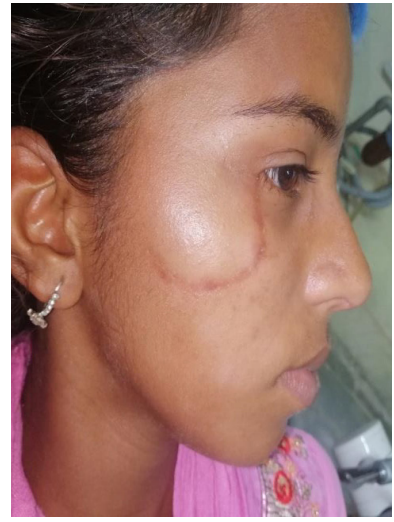

Figure 4. Wound healing at 3 months follow up. was intact; still any foreign body using radiographs and manual exploration of the wound.

Management of a patient with pressure cooker related injuries follows the principle similar to patients sustaining blast injuries. The primary goal is to resuscitate the patient and maintain the airway and hemodynamic status after which definite management can be performed. ${ }^{8}$ Though, this is an uncommon cause of maxillofacial injury in children, one must be prepared to manage such case. Accidental domestic pressure explosion can result in serious and potentially life threatening injuries. Based on the available literature it is difficult to ascertain whether these injuries are less common or have not been well addressed in the literature. Though uncommon, these injuries are life threatening, devastating and disfiguring so management of these cases should follow appropriate guidelines. These are preventable injuries, thus education for making the public aware regarding such mishaps should be a part of awareness campaigns.

\section{CONGLUSIONS}

A rare case of maxillofacial injury in pediatric population involving pressure cooker blast injury was reported where the child was managed effectively with proper wound exploration and debridement followed by multilayered suturing. Satisfactory healing was observed on regular follow up and patient is still under follow up in dermatology department.

Conflict of Interest: None 


\section{REFERENCES}

1. Mukherjee CG, Mukherjee U. Maxillofacial Trauma in Children. Int J Clin Pediatr Dent 2012;5(3):231-236. [PubMed I DOI]

2. Atreya A, Kanchan T, Nepal S. Pressure Cooker-A Potential Hazard in Domestic Setting. Kathmandu University Medical Journal (KUMJ). 2016 AprJun;14(54):181. [ubMed I Full Text]

3. Singh AK, Ditkofsky NG, York JD, Abujudeh HH, Avery LA, Brunner JF, Sodickson AD, Lev MH. Blast Injuries: From Improvised Explosive Device Blasts to the Boston Marathon Bombing. Radiographics. 2016 Jan-Feb;36(1):295-307. [PubMed I DOI]

4. Das JM, Pokharel A, Sapkota R, Mishra M, Aryal AB. Case Report: Two cases of rare head injuries from Nepal [version 1; peer review: 1 approved]. F1000Research. 2018 Sep;7:1483. [Full Text I DOI]

5. Bilukha OO, Becknell K, Laurenge H, Danee L, Subedi KP. Fatal and non-fatal injuries due to intentional explosions in Nepal, 2008-2011: analysis of surveillance data. Confl Health. 2013 Mar 20;7(1):5. [PubMed I DOI]

6. Post Report. Nepal Army team defuses 'pressure-cooker bomb' at Syuchatar. The Kathmandu Post. 2019 Mar 10. Retrieved 22 July 2020. Available from: https://kathmandupost.com/national/2019/03/10/nepal-army-team-defuses-pressure-cooker-bomb-at-syuchatar. [Link]

7. Post Report. Bomb goes off in Bharatpur. The Kathmandu Post. 2018 May 13. Retrieved 22 July 2020. Available from: https:/kathmandupost.com/national/2018/05/13/ bomb-goes-off-in-bharatpur. [Link]

8. Calderon-Miranda WG, Escobar-Hernandez N, Moscote-Salazar LR, Rubiano AM, Blancas-Rivera MA, Agrawal A, Carmona-Meza Z, Alvis-Miranda HR, AlcalaCerra G. Traumatic brain injury due to pressure cooker explosion in a child: Case report. Romanian Neurosurgery. 2016 Jun;30(2):300-2. [Full Text] 